\title{
HSP60 speaks to the immune system in many voices
}

\author{
Francisco J. Quintana and Irun R. Cohen* \\ Center for Neurologic Diseases, Harvard Medical School, Boston, MA 02115, USA and *Department \\ of Immunology, The Weizmann Institute of Science, Rehovot 76100, Israel
}

\begin{abstract}
Heat shock proteins (HSP) were initially identified as a family of stress-induced proteins characterized by their chaperone activity. HSP, however, are also important players in the control of the immune response: HSP are targeted by HSP-specific T cells and antibodies in healthy subjects and also during the course of autoimmune disorders and, conversely, HSP influence the activity of several immune cell types via innate receptor signalling pathways. In addition, the immune response to HSP can be mined for information on the state of the immune system. Newborns carry autoantibodies to HSP. However, this natural autoreactivity to HSP is modified by inflammation, and these changes can be monitored as biomarkers during postnatal life. Using antigen microarrays, we have shown that autoantibody patterns identify individuals prone to develop autoimmune diabetes before disease onset. Moreover, changes in the inflammatory process in multiple sclerosis are also reflected in the antibody response to self-HSP. Herein, we discuss the relevance of HSP and their immune activities for the regulation and monitoring of inflammation and autoimmune disease.
\end{abstract}

2008 The biology of extracellular molecular chaperones. Wiley, Chichester (Novartis Foundation Symposium 291) p 101-114

Heat shock proteins (HSPs) were initially identified as a heterogeneous family of stress-induced proteins required to assist the folding of polypeptides into mature proteins in routine protein synthesis, in normal transport of proteins across membranes and in response to protein denaturation during cell stress (Hartl \& Hayer-Hartl 2002). However, in addition to their intracellular chaperone function, HSPs establish a two-way dialogue with the immune system: HSPs are targeted by HSP-specific T cells and antibodies in healthy subjects and also during the course of autoimmune disorders and, conversely, HSPs influence the activity of several immune cell types. In this chapter, we discuss several aspects of this dialogue and postulate that its comprehension is of importance for our ability to prevent, treat and monitor human autoimmune disorders. 


\section{The immune system talks to HSPs: HSPs as targets of adaptive immunity}

HSPs are targets of the physiological immune response. Microbial HSPs were initially identified as a common dominant antigen recognized by the immune system of subjects infected with different micro-organisms (Young et al 1987). Soon afterwards, self-HSPs were found to be targeted by the immune system in response to inflammation (van Eden et al 1988, Anderton et al 1993). These initial studies paved the way to the identification of HSPs as a target of pathogenic and regulatory immune responses.

\section{HSP as a target of pathogenic $T$ and $B$ cell responses}

Adjuvant arthritis (AA) is an autoimmune disease inducible in Lewis rats by immunization with killed Mycobacterium tuberculosis (Wauben et al 1994). T cell clones cross-reactive with cartilage and mycobacteria transfer arthritis to irradiated rats (Holoshitz et al 1984, van Eden et al 1985). The antigen recognized by the pathogenic clones was identified as the 180-188 region (mt180) of the mycobacterial $65 \mathrm{kDa}$ HSP (Hsp65) (van Eden et al 1988), suggesting that Hsp65 bore an epitope cross-reactive with a joint self-epitope (van Eden et al 1985). Autoimmune T cell responses directed against the mammalian counterpart of Hsp65, the $60 \mathrm{kDa}$ HSP (Hsp60) and also against other HSPs, have also been characterized in human arthritis (Blass et al 2001, Corrigall et al 2001, de Kleer et al 2003, Macht et al 2000).

NOD mice develop diabetes as a consequence of a spontaneous T cell-mediated autoimmune process that destroys the insulin-producing $\beta$ cells (Tisch \& McDevitt 1996). NOD mice have a high frequency of self-reactive T cells, which is reflected by a highly self-reactive B cell repertoire (Quintana \& Cohen 2001, Quintana et al 2004c). Several antigens are targeted by diabetogenic $T$ cells including insulin (Wegmann et al 1994) and glutamic acid decarboxylase (GAD) (Tisch et al 1993). The connection of HSPs to autoimmune disease was confirmed when it was discovered that Hsp60 is targeted by T and B cells in spontaneous autoimmune NOD diabetes (Elias et al 1990). Moreover, anti-Hsp60 T-cell clones induce diabetes in irradiated NOD mice (Elias et al 1990), and immunization with the 437-460 immunodominant T cell epitope of Hsp60 (p277) can trigger transient insulitis and hyperglycaemia in standard strains of mice (Elias et al 1995). The relevance of HSPs for human autoimmune diabetes was highlighted by the finding of $\mathrm{B}$ and T cell responses to Hsp60 and p277 in autoimmune diabetes patients (AbulafiaLapid et al 1999, 2003, Sobel \& Creswell 2006, Szebeni et al 2005).

Autoimmunity to HSPs also characterizes atherosclerosis (Wick 2000), Bechet's disease (Lehner 1997), systemic lupus erythematosus (Dhillon et al 1991), and 
other inflammatory and non-inflammatory disorders. These findings point to the importance of HSPs in autoimmune disorders, and suggest that HSP-specific T cell responses might be targeted for the management of pathogenic autoimmunity.

\section{HSPs as a target of regulatory responses}

Although it was shown that HSP-specific T cells can transfer autoimmune arthritis (AA) (Holoshitz et al 1984, van Eden et al 1985) or diabetes (Elias et al 1990), it was soon realized that immunity to HSPs is a double-edged sword with the power not only to drive but also to dampen autoimmune disorders.

Hsp65 administered as a protein (Billingham et al 1990), encoded in a recombinant vaccinia virus (Hogervorst et al 1991) or as a DNA vaccine (Ragno et al 1997) can inhibit AA. The administration of HSP65 can also regulate other experimental models of arthritis, triggered either by the lipoidal amine CP20961 (Anderton et al 1995) or by pristane (Thompson et al 1998). Inhibition of AA by Hsp65 involves cross-reactivity with self-Hsp60 (van Eden et al 2005). We studied the specificity of the regulatory immune response that controls AA using DNA vaccines coding for human HSP60 (pHSP60) or mycobacterial Hsp65 (pHsp65) (Quintana et al 2002). Although both pHSP60 or pHsp65 protected against AA, pHSP60 was significantly more effective (Quintana et al 2002). We used DNA vaccines encoding fragments of HSP60 to identify immunoregulatory regions within HSP60. The anti-arthritogenic effects of the PHSP60 construct resided in the region of amino acids 1-260 of HSP60 (Quintana et al 2003a). Using HSP60derived overlapping peptides, we identified peptide Hu3 (amino acids 31-50 of HSP60) which was specifically recognized by the $T$ cells of rats protected from AA by DNA-vaccination (Quintana et al 2003a). Vaccination with Hu3, or transfer of splenocytes from Hu3-vaccinated rats, prevented the development of AA, while vaccination with the mycobacterial homologue of Hu3 had no effect (Quintana et al 2003a). Prevention of AA by vaccination with $\mathrm{pHSP} 60$, DNA vaccines encoding the N-terminus of HSP60, or Hu3 was associated with the induction of T cells that secreted IFN $\gamma$, IL10 and TGFß1 upon stimulation with HSP60 (Quintana et al 2002, 2003a). Thus, HSP60-specific T cells can control the progression of AA. Moreover, using DNA vaccines encoding the human $70 \mathrm{kDa}$ heat shock protein (HSP70) or the human $90 \mathrm{kDa}$ heat shock protein (HSP90), we showed that HSPs other than HSP60 can also inhibit AA. We found that DNA vaccination with HSP70 or HSP90 shifted the specific arthritogenic T-cell response from a Th1 to a Th2/3 phenotype and inhibited AA (Quintana et al 2004b). Thus, HSP70 and HSP90, and not only HSP60, can modulate arthritogenic $\mathrm{T}$ cell responses in AA.

In humans, HSP60-specific immune responses in rheumatoid arthritis and juvenile chronic arthritis (Macht et al 2000, Prakken et al 1996) patients are associated 
with a better prognosis and milder symptoms. Indeed human HSP-specific regulatory $\mathrm{T}$ cells have been characterized in arthritis patients (Kamphuis et al 2005, Massa et al 2007). All in all, these studies demonstrated that immunity to HSP is beneficial for the regulation of AA. Work with HSP60 in autoimmune diabetes strengthened this view.

Vaccination of NOD mice with the p277 peptide of HSP60 arrested the development of diabetes (Elias et al 1991) and even induced the remission of overt hyperglycaemia (Elias \& Cohen 1994). Successful p277 treatment was associated with the down-regulation of spontaneous $\mathrm{T}$ cell reactivity to p277 and with the induction of antibodies to p277 displaying Th2-like isotypes IgG1 and IgG2b (Elias et al 1997). Other peptides of HSP60 could also inhibit the development of spontaneous diabetes in NOD mice (Bockova et al 1997).

NOD mice can also develop a more robust form of diabetes upon the administration of cyclophosphamide-cyclophosphamide-accelerated diabetes (CAD) (Yasunami \& Bach 1988). We used DNA vaccination with constructs encoding human HSP60 (pHSP60) or mycobacterial Hsp65 (pHsp65) to explore the regulatory role of HSP60 (Quintana et al 2003a). Vaccination with pHSP60 protected NOD mice from CAD. In contrast, vaccination with $\mathrm{pHsp} 65$, with an empty vector or with a $\mathrm{CpG}$-positive oligonucleotide was not effective, suggesting that efficacy of the pHSP60 construct might be based on regulatory HSP60 epitopes not shared with its mycobacterial counterpart, Hsp65 (Quintana et al 2003a).

Vaccination with pHSP60 modulated the T cell responses to HSP60, and also to GAD and insulin: T cell proliferative responses were significantly reduced and the pattern of cytokine secretion to HSP60, GAD and insulin showed an increase in IL10 and IL5 secretion and a decrease in IFN $\gamma$ secretion, compatible with a shift from a Th1-like towards a Th2-like autoimmune response (Quintana et al 2003a). Thus, immunoregulatory networks activated by vaccination with pHSP60 or p277 can spread to other B cell antigens such as insulin and GAD, and can control NOD diabetes.

Human autoimmune diabetes was susceptible to immunomodulation by p277 therapy. A double-blind, phase II clinical trial was designed to study the effects of p277 therapy on newly diagnosed patients (Raz et al 2001, 2007). The administration of p277 after the onset of clinical diabetes preserved the endogenous levels of C-peptide (which fell in the placebo group) and was associated with lower requirements for exogenous insulin, revealing the arrest of inflammatory $\beta$-cell destruction (Raz et al 2001, 2007). Treatment with p277 was associated with an enhanced Th2 response to HSP60 and p277 (Raz et al 2001). Encouraging results of treatment with p277 were later obtained in an independent clinical trial (Huurman et al 2007).

In conclusion, the administration of HSP60 peptides, or of whole HSP60 as a recombinant protein or a DNA vaccine, can halt autoimmune diabetes. Several 
antigens are targeted during the progression of diabetes (Tisch \& McDevitt 1996). Thus, it is remarkable that HSP60-triggered immunoregulation controls the immune reactivity to non-cross-reactive autoantigens such as insulin and GAD.

\section{HSP60 as a target of anti-ergotypic regulatory $T$ cells}

To exploit the immune properties of HSP60 for the treatment of autoimmune disorders, we have first to understand the mechanisms by which HSP60 can affect autoimmunity to other molecules. The identification of HSP60 as a target of antiergotypic regulatory $\mathrm{T}$ cells started to unveil these mechanisms.

$\mathrm{T}$ cells reactive to activated $\mathrm{T}$ cells (but not to resting $\mathrm{T}$ cells) can control experimental autoimmune disease (Lohse et al 1989, Mimran et al 2004, 2005, Mor et al 1996). The $\mathrm{T}$ cell receptor of these regulatory $\mathrm{T}$ cells recognizes peptides derived from activation markers (ergotopes), such as the $\alpha$-chain of the IL2 receptor (Mimran et al 2004, Mor et al 1996) or the TNF $\alpha$ receptor (Mor et al 1996). These cells are termed anti-ergotypic (Lohse et al 1989, Quintana \& Cohen 2006). HSP expression is also up-regulated upon T cell activation (Ferris et al 1988). Thus, HSP60 might serve as an ergotope. We studied whether vaccination with DNA vaccines encoding HSP60, or with the regulatory peptide Hu3, might induce anti-ergotypic responses. To serve as an ergotope, HSP60 would have to fulfil two requirements. First, HSP60 must be up-regulated in activated T cells. Second, activated $\mathrm{T}$ cells must present HSP60-derived peptides to HSP60-specific regulatory $\mathrm{T}$ cells.

The activation of $\mathrm{T}$ cells by mitogenic Con $\mathrm{A}$ or by specific antigen up-regulates intracellular levels of HSP60 (Cohen et al 2004, Quintana \& Cohen 2006). Thus, the first condition is fulfilled: T cell activation triggers HSP60 expression. Moreover, activated T cells can present HSP60. HSP60-specific T cells proliferated to activated T cells and secreted both IFN $\gamma$ and TGF $\beta 1$ (Cohen et al 2004, Quintana \& Cohen 2006). The activation of HSP60-specific T cells was MHC class II (RT1. B) restricted, since it could be inhibited with the OX6 (Wick 2000) monoclonal antibody (Cohen et al 2004, Quintana \& Cohen 2006). Thus, HSP60 could function as an ergotope in vitro; however, can functional HSP60-specific anti-ergotypic responses be induced in vivo?

DNA vaccination with pHSP60 was found to induce anti-ergotypic $\mathrm{T}$ cell responses, MHC class II (RT1.B) and MHC class I restricted. Vaccination with Hu3 induced only an MHC class II restricted (RT1.B) anti-ergotypic T cell response (Cohen et al 2004, Quintana \& Cohen 2006). Thus, Hsp60-specific CD4 ${ }^{+}$and $\mathrm{CD} 8{ }^{+}$anti-ergotypic $\mathrm{T}$ cells can be induced in vivo.

Lymph node cells (LNCs) of AA rats stimulated with the immunodominant 180-88 T cell epitope of Hsp65 (mt180) secrete high levels of IFN $\gamma$ (Cohen et al 2004, Quintana \& Cohen 2006). Since T cells specific for this epitope have been 
shown to transfer AA (van Eden et al 1988), the reactivity of LNC of AA to mt180 is thought to reflect the behaviour of the arthritogenic T cells. LNCs of AA rats stimulated with mt180 in the presence of Hsp60-specific anti-ergotypic T cells (but not with a control anti-MBP line) secreted significantly less IFN $\gamma$. Moreover, the transfer of Hsp60-specific anti-ergotypic T cells led to a significant decrease in the severity of AA. Thus, anti-ergotypic responses can control the arthritogenic response in vitro and in vivo.

\section{HSP talks to the immune system: innate functions of HSP}

Several lines of research suggest that HSP can have a broad range of effects on the innate immune response (reviewed in Quintana \& Cohen 2005). HSP60 and p277 can directly inhibit chemotaxis and activate anti-inflammatory programmes in human T cells, via toll-like receptor (TLR)2 (Zanin-Zhorov et al 2003), and can also modify B cell behaviour (Cohen-Sfady et al 2005). However, due to space limitations, we will focus our discussion on the direct effects of HSP on $\mathrm{CD} 4{ }^{+} \mathrm{CD} 25^{+}$regulatory $\mathrm{T}$ cells (Treg).

HSPs are endogenous ligands for innate receptors. HSP60 and HSP70 activate TLR4 and TLR2 (Vabulas et al 2002). Caramalho and colleagues reported that Treg can be activated via TLR4 by bacterial lipopolysaccharide (Caramalho et al 2003). Thus, it was conceivable that self-HSP might activate Treg through TLR. Indeed, we found that HSP60 acts as a costimulator of human Treg (Zanin-Zhorov et al 2006). Treatment of Treg with HSP60 or p277 significantly enhanced their ability to inhibit the activation of $\mathrm{CD} 4{ }^{+} \mathrm{CD} 25^{-}$or $\mathrm{CD} 8^{+}$effector $\mathrm{T}$ cells in terms of proliferation and IFN $\gamma$ and $\mathrm{TNF} \alpha$ secretion. The effects of HSP60 on Treg involved TLR2-dependent signalling pathways that led to the activation of PKC, PI3K and p38. HSP60-treated Treg suppressed effector T cells both by cell-to-cell contact and by secretion of TGF $\beta 1$ and IL10. Thus, HSP60 boosts the suppressive activity of Treg via TLR2 signalling.

\section{Immune system and HSP dialogue as an inflammation biomarker}

Antibodies are of interest for the study of autoimmunity because they might play pathological roles, and also because IgG antibodies can reflect the activity of the T cell compartment. Since it is easier to assay antibodies than antigen-specific T cells, efforts have been invested to develop new technologies to monitor antibody repertoires (Quintana et al 2004c, Robinson et al 2002).

Antigen microarrays are newly developed tools for the high-throughput characterization of the immune response that have been shown to be useful for the study of autoimmunity (Quintana et al 2004c, 2006, Robinson et al 2002). Healthy humans and mice are born with low levels of self-reactive antibodies (Coutinho 
et al 1995, Quintana \& Cohen 2004). These natural autoantibody repertoires can be mined for information regarding the state of the immune response (Cohen 2007). By studying different mouse strains, we found that natural autoantibodies are indicators of susceptibility to the future development of various autoimmune diseases (Quintana et al 2003b, 2004a, 2004c, Quintana \& Cohen 2001, 2004). Moreover, patterns of natural antibodies can be used to identify individuals prone to develop autoimmune disorders later in life. Approximately $50 \%$ of the male NOD mice in our colony develop diabetes following administration of cyclophosphamide (Quintana et al 2004c). We have used antigen microarrays to identify the individual NOD mice that will develop diabetes by studying serum samples taken before treatment with cyclophosphamide (Quintana et al 2004c). Based on the role played by Hsp60 in the immunoregulation of NOD diabetes (Cohen 1997, Cohen et al 2003), we included along with other diabetes-associated antigens, recombinant heat shock proteins, and peptide libraries covering the whole sequence of the $60 \mathrm{kDa}$ and the $70 \mathrm{kDa}$ heat shock proteins (HSP60 and HSP70, respectively). By analysing the antibody repertoire of each mouse, we could identify healthy mice that later developed autoimmune diabetes, (Quintana et al 2004c). Interestingly, the presence of antibodies to HSP60 and HSP70 were central in the identification of the individuals that would later become diabetic.

We have recently used antigen arrays to study the immune response in multiple sclerosis (MS). MS is a chronic inflammatory disease of the CNS of presumed autoimmune aetiology (Sospedra \& Martin 2005, Weiner 2004). Approximately $85-90 \%$ of patients begin with a relapsing-remitting (RRMS) course; in the remaining patients, MS presents a primary progressive course (PPMS). There is compelling evidence that immune processes play a major role in MS pathogenesis and progression (Sospedra \& Martin 2005, Weiner 2004), and that inflammation outweighs neurodegeneration in the RRMS, but not in the progressive forms of the disease (Hauser \& Oksenberg 2006). However, to date there has been no reliable method to characterize the complex immune processes that are unique to MS. Reactivity to HSP, however, has been described in MS (Aquino et al 1997, Gao et al 1995 Ousman et al 2007 Selmaj et al 1992) and experimental autoimmune encephalomyelitis (EAE) (Mor \& Cohen 1992). We used antigen arrays to analyse the antibody response in MS, and we found specific immune responses directed against CNS proteins and lipids (Quintana et al, submitted); strikingly HSP-specific antibodies characterized RRMS but not PPMS (Quintana et al, submitted). Thus, antibodies to HSPs might be useful biomarkers to monitor inflammation in MS.

\section{Conclusions}

All in all, the results discussed here point to an ongoing dialogue between the immune system and HSPs, which results in the regulation of the immune response. 
Our characterization of this dialogue provides us with a tool to monitor the immune state of a subject. Moreover, strategies aimed at exploiting this ongoing dialogue have the potential to constitute new strategies for the management of autoimmune disease; our successful initial results on the treatment of autoimmune diabetes supports this view.

\section{References}

Abulafia-Lapid R, Elias D, Raz I, Keren-Zur Y, Atlan H, Cohen IR 1999 T cell proliferative responses of type 1 diabetes patients and healthy individuals to human hsp60 and its peptides. J Autoimmun 12:121-129

Abulafia-Lapid R, Gillis D, Yosef O, Atlan H, Cohen IR 2003 T cells and autoantibodies to human HSP70 in type 1 diabetes in children. J Autoimmun 20:313-321

Anderton SM, van der Zee R, Goodacre JA 1993 Inflammation activates self hsp60-specific T cells. Eur J Immunol 23:33-38

Anderton SM, van der Zee R, Prakken B, Noordzij A, van Eden W 1995 Activation of T cells recognizing self $60-\mathrm{kD}$ heat shock protein can protect against experimental arthritis. J Exp Med 181:943-952

Aquino DA, Capello E, Weisstein J et al 1997 Multiple sclerosis: altered expression of 70- and 27-kDa heat shock proteins in lesions and myelin. J Neuropathol Exp Neurol 56:664-672

Billingham ME, Carney S, Butler R, Colston MJ 1990 A mycobacterial 65-kD heat shock protein induces antigen-specific suppression of adjuvant arthritis, but is not itself arthritogenic. J Exp Med 171:339-344

Blass S, Union A, Raymackers J et al 2001 The stress protein BiP is overexpressed and is a major B and T cell target in rheumatoid arthritis. Arthritis Rheum 44:761-771

Bockova J, Elias D, Cohen IR 1997 Treatment of NOD diabetes with a novel peptide of the hsp60 molecule induces Th2-type antibodies. J Autoimmun 10:323-329

Caramalho I, Lopes-Caravalho T, Ostler D, Zelenay S, Haury M, Demengeot J 2003 Regulatory T cells selectively express toll-like receptors and are activated by lipopolysaccharide. J Exp Med 197:403-411

Cohen IR 1997 Questions about NOD mouse diabetes. Res Immunol 148:286-291

Cohen IR 2007 Real and artificial immune systems: computing the state of the body. Nat Rev Immunol 7:569-574

Cohen IR, Quintana FJ, Nussbaum G, Cohen M, Zanin A, Lider O 2003 HSP60 and the regulation of inflammation: physiological and pathological. In: van Eden W (ed) Heat shock proteins and inflammation. Basel: Birkhauser Verlag AG, p 1-13

Cohen IR, Quintana FJ, Mimran A 2004 Tregs in T cell vaccination: exploring the regulation of regulation. J Clin Invest 114:1227-1232

Cohen-Sfady M, Nussbaum G, Pevsner-Fischer M et al 2005 Heat shock protein 60 activates B cells via the TLR4-MyD88 pathway. J Immunol 175:3594-3602

Corrigall VM, Bodman-Smith MD, Fife MS et al 2001 The human endoplasmic reticulum molecular chaperone $\mathrm{BiP}$ is an autoantigen for rheumatoid arthritis and prevents the induction of experimental arthritis. J Immunol 166:1492-1498

Coutinho A, Kazatchkine MD, Avrameas S 1995 Natural autoantibodies. Curr Opin Immunol 7:812-818

de Kleer IM, Kamphuis SM, Rijkers GT et al 2003 The spontaneous remission of juvenile idiopathic arthritis is characterized by CD30+ T cells directed to human heat-shock protein 60 capable of producing the regulatory cytokine interleukin-10. Arthritis Rheum 48:20012010 
Dhillon V, Latchman D, Isenberg D 1991 Heat shock proteins and systemic lupus erythematosus. Lupus 1:3-8

Elias D, Cohen IR 1994 Peptide therapy for diabetes in NOD mice. Lancet 343:704-706

Elias D, Markovits D, Reshef T, van der Zee R, Cohen IR 1990 Induction and therapy of autoimmune diabetes in the non-obese diabetic (NOD/Lt) mouse by a $65-\mathrm{kDa}$ heat shock protein. Proc Natl Acad Sci USA 87:1576-1580

Elias D, Reshef T, Birk OS, van der Zee R, Walker MD, Cohen IR 1991 Vaccination against autoimmune mouse diabetes with a T-cell epitope of the human $65-\mathrm{kDa}$ heat shock protein. Proc Natl Acad Sci USA 88:3088-3091

Elias D, Marcus H, Reshef T, Ablamunits V, Cohen IR 1995 Induction of diabetes in standard mice by immunization with the p277 peptide of a $60-\mathrm{kD}$ a heat shock protein. Eur J Immunol 25:2851-2857

Elias D, Meilin A, Ablamunits V et al 1997 Hsp60 peptide therapy of NOD mouse diabetes induces a Th2 cytokine burst and downregulates autoimmunity to various beta-cell antigens. Diabetes 46:758-764

Ferris DK, Harel-Bellan A, Morimoto RI, Welch WJ, Farrar WL 1988 Mitogen and lymphokine stimulation of heat shock proteins in $\mathrm{T}$ lymphocytes. Proc Natl Acad Sci USA $85: 3850-3854$

Gao YL, Brosnan CF, Raine CS 1995 Experimental autoimmune encephalomyelitis. Qualitative and semiquantitative differences in heat shock protein 60 expression in the central nervous system. J Immunol 154:3548-3556

Hartl FU, Hayer-Hartl M 2002 Molecular chaperones in the cytosol: from nascent chain to folded protein. Science 295:1852-1858

Hauser SL, Oksenberg JR 2006 The neurobiology of multiple sclerosis: genes, inflammation, and neurodegeneration. Neuron 52:61-76

Hogervorst EJ, Schouls L, Wagenaar JP et al 1991 Modulation of experimental autoimmunity: treatment of adjuvant arthritis by immunization with a recombinant vaccinia virus. Infect Immun 59:2029-2035

Holoshitz J, Matitiau A, Cohen IR 1984 Arthritis induced in rats by cloned T lymphocytes responsive to mycobacteria but not to collagen type II. J Clin Invest 73:211-215

Huurman VA, Decochez K, Mathieu C, Cohen IR, Roep BO 2007 Therapy with the hsp60 peptide DiaPep277 in C-peptide positive type 1 diabetes patients. Diabetes Metab Res Rev 23:269-275

Kamphuis S, Kuis W, de Jager W et al 2005 Tolerogenic immune responses to novel T-cell epitopes from heat-shock protein 60 in juvenile idiopathic arthritis. Lancet 366:50 56

Lehner T 1997 The role of heat shock protein, microbial and autoimmune agents in the aetiology of Behcet's disease. Int Rev Immunol 14:21-32

Lohse AW, Mor F, Karin N, Cohen IR 1989 Control of experimental autoimmune encephalomyelitis by $\mathrm{T}$ cells responding to activated T cells. Science 244:820-822

Macht LM, Elson CJ, Kirwan JR et al 2000 Relationship between disease severity and responses by blood mononuclear cells from patients with rheumatoid arthritis to human heat-shock protein 60. Immunology 99:208-214

Massa M, Passalia M, Manzoni SM et al 2007 Differential recognition of heat-shock protein dnaJ-derived epitopes by effector and Treg cells leads to modulation of inflammation in juvenile idiopathic arthritis. Arthritis Rheum 56:1648-1657

Mimran A, Mor F, Carmi P, Quintana FJ, Rotter V, Cohen IR 2004 DNA vaccination with CD25 protects rats from adjuvant arthritis and induces an antiergotypic response. J Clin Invest 113:924-932

Mimran A, Mor F, Quintana FJ, Cohen IR 2005 Anti-ergotypic T cells in naive rats. J Autoimmun 24:191-201 
Mor F, Cohen IR 1992 T cells in the lesion of experimental autoimmune encephalomyelitis. Enrichment for reactivities to myelin basic protein and to heat shock proteins. J Clin Invest $90: 2447-2455$

Mor F, Reizis B, Cohen IR, Steinman L 1996 IL-2 and TNF receptors as targets of regulatory T-T interactions: isolation and characterization of cytokine receptor-reactive $\mathrm{T}$ cell lines in the Lewis rat. J Immunol 157:4855-4861

Ousman SS, Tomooka BH, van Noort JM et al 2007 Protective and therapeutic role for alphaBcrystallin in autoimmune demyelination. Nature 448:474-479

Prakken AB, van Eden W, Rijkers GT et al 1996 Autoreactivity to human heat-shock protein 60 predicts disease remission in oligoarticular juvenile rheumatoid arthritis. Arthritis Rheum 39:1826-1832

Quintana FJ, Cohen IR 2001 Autoantibody patterns in diabetes-prone NOD mice and in standard C57BL/6 mice. J Autoimmun 17:191-197

Quintana FJ, Cohen IR 2004 The natural autoantibody repertoire and autoimmune disease. Biomed Pharmacother 58:276-281

Quintana FJ, Cohen IR 2005 Heat shock proteins as endogenous adjuvants in sterile and septic inflammation. J Immunol 175:2777-2782

Quintana FJ, Cohen IR 2006 Anti-ergotypic immunoregulation. Scand J Immunol 64:205-210

Quintana FJ, Carmi P, Mor F, Cohen IR 2002 Inhibition of adjuvant arthritis by a DNA vaccine encoding human heat shock protein 60. J Immunol 169:3422-3428

Quintana FJ, Carmi P, Mor F, Cohen IR 2003a DNA fragments of human HSP60 vaccinate against adjuvant arthritis: identification of a regulatory HSP60 peptide. J Immunol 171: 3533-3541

Quintana FJ, Pitashny M, Cohen IR 2003b Experimental autoimmune myasthenia gravis in naive non-obese diabetic (NOD/LtJ) mice: susceptibility associated with natural $\operatorname{IgG}$ antibodies to the acetylcholine receptor. Int Immunol 15:11-16

Quintana FJ, Buzas E, Prohaszka Z et al 2004a Knock-out of the histidine decarboxylase gene modifies the repertoire of natural autoantibodies. J Autoimmun 22:297-305

Quintana FJ, Carmi P, Mor F, Cohen IR 2004b Inhibition of adjuvant-induced arthritis by DNA vaccination with the $70-\mathrm{kd}$ or the $90-\mathrm{kd}$ human heat-shock protein: immune cross-regulation with the 60-kd heat-shock protein. Arthritis Rheum 50:3712-3720

Quintana FJ, Hagedorn PH, Elizur G, Merbl Y, Domany E, Cohen IR 2004c Functional immunomics: microarray analysis of $\operatorname{IgG}$ autoantibody repertoires predicts the future response of mice to induced diabetes. Proc Natl Acad Sci USA 101 Suppl 2:14615-14621

Quintana FJ, Merbl Y, Sahar E, Domany E, Cohen IR 2006 Antigen-chip technology for accessing global information about the state of the body. Lupus 15:428-430

Ragno S, Colston MJ, Lowrie DB, Winrow VR, Blake DR, Tascon R 1997 Protection of rats from adjuvant arthritis by immunization with naked DNA encoding for mycobacterial heat shock protein 65. Arthritis Rheum 40:277-283

Raz I, Elias D, Avron A, Tamir M, Metzger M, Cohen IR 2001 Beta-cell function in new-onset type 1 diabetes and immunomodulation with a heat-shock protein peptide (DiaPep277): a randomised, double-blind, phase II trial. Lancet 358:1749-1753

Raz I, Avron A, Tamir M, Metzger M et al 2007 Treatment of new-onset type 1 diabetes with peptide DiaPep277 is safe and associated with preserved beta-cell function: extension of a randomized, double-blind, phase II trial. Diabetes Metab Res Rev 23:292-298

Robinson WH, DiGennaro C, Hueber W et al 2002 Autoantigen microarrays for multiplex characterization of autoantibody responses. Nat Med 8:295-301

Selmaj K, Brosnan CF, Raine CS 1992 Expression of heat shock protein- 65 by oligodendrocytes in vivo and in vitro: implications for multiple sclerosis. Neurology 42:795-800

Sobel DO, Creswell K 2006 Characterization of anti-islet cytotoxic human T-cell clones from patients with type 1 diabetes mellitus. Autoimmunity 39:323-332 
Sospedra M, Martin R 2005 Immunology of multiple sclerosis. Annu Rev Immunol 23:683-747

Szebeni A, Schloot N, Kecskemeti V et al 2005 Th1 and Th2 cell responses of type 1 diabetes patients and healthy controls to human heat-shock protein 60 peptides AA437-460 and AA394-408. Inflamm Res 54:415-419

Thompson SJ, Francis JN, Siew LK et al 1998 An immunodominant epitope from mycobacterial $65-\mathrm{kDa}$ heat shock protein protects against pristane-induced arthritis. J Immunol 160:4628-4634

Tisch R, McDevitt H 1996 Insulin-dependent diabetes mellitus. Cell 85:291-297

Tisch R, Yang XD, Singer SM, Liblau RS, Fugger L, McDevitt HO 1993 Immune response to glutamic acid decarboxylase correlates with insulitis in non-obese diabetic mice. Nature $366: 72-75$

Vabulas RM, Braedel S, Hilf N et al 2002 The endoplasmic reticulum-resident heat shock protein Gp96 activates dendritic cells via the Toll-like receptor 2/4 pathway. J Biol Chem 277:20847-20853

van Eden W, Holoshitz J, Nevo Z, Frenkel A, Klajman A, Cohen IR 1985 Arthritis induced by a T-lymphocyte clone that responds to Mycobacterium tuberculosis and to cartilage proteoglycans. Proc Natl Acad Sci USA 82:5117-5120

van Eden W, Thole JE, van der Zee R et al 1988 Cloning of the mycobacterial epitope recognized by $T$ lymphocytes in adjuvant arthritis. Nature 331:171-173

van Eden W, van der Zee R, Prakken B 2005 Heat-shock proteins induce T-cell regulation of chronic inflammation. Nat Rev Immunol 5:318-330

Wauben MHM, Wagenaar-Hilbers JPA, van Eden W 1994 Adjuvant arthritis. In: Cohen IR, Miller A (eds) Autoimmune disease models. Academic Press Inc. p 201-216

Wegmann DR, Norbury-Glaser M, Daniel D 1994 Insulin-specific T cells are a predominant component of islet infiltrates in pre-diabetic NOD mice. Eur J Immunol 24:1853-1857

Weiner HL 2004 Multiple sclerosis is an inflammatory T-cell-mediated autoimmune disease. Arch Neurol 61:1613-1615

Wick G 2000 Atherosclerosis - an autoimmune disease due to an immune reaction against heat-shock protein 60. Herz 25:87-90

Yasunami R, Bach JF 1988 Anti-suppressor effect of cyclophosphamide on the development of spontaneous diabetes in NOD mice. Eur J Immunol 18:481-484

Young DB, Ivanyi J, Cox JH, Lamb JR 1987 The $65 \mathrm{kDa}$ antigen of mycobacteria-a common bacterial protein? Immunol Today 8:215-219

Zanin-Zhorov A, Nussbaum G, Franitza S, Cohen IR, Lider O 2003 T cells respond to heat shock protein 60 via TLR2: activation of adhesion and inhibition of chemokine receptors. FASEB J 17:1567-1569

Zanin-Zhorov A, Cahalon L, Tal G, Margalit R, Lider O, Cohen IR 2006 Heat shock protein 60 enhances CD4+ CD25+ regulatory $\mathrm{T}$ cell function via innate TLR2 signaling. J Clin Invest 116:2022-2032

\section{DISCUSSION}

Gaston: I am interested in whether endogenous Hsp60, which you showed to be up-regulated, is actually presented by these T cells. In your experiments you demonstrated the ability of the class II-expressing $\mathrm{T}$ cell to present exogenous HSP.

Quintana: There wasn't any exogenous HSP. They were just activated T cells that were up-regulating their endogenous levels of Hsp60, used as APCs (antigen 
presenting cells). I raised the clones by immunization with the same antigen, but then I used the clones as probes to see whether the endogenous Hsp60 was being presented in the membrane.

Gaston: How does that endogenous Hsp60 get into the class II pathway? Does it have to be excreted first?

Quintana: Which one is the HSP that is being presented? Is it the one that we saw (up-regulated by western blot) that might be in the membrane? I have no idea. What I do know is that if you treat those $\mathrm{T}$ cells with different cytokines, these are known to affect antigen processing, and this leads to the presentation of different epitopes of Hsp60. We still have no clue about the molecular mechanism for this.

Macario: Is the proteasome a mediator of this antigen processing and presentation for Hsp60? We know that Hsp70 can interact with the proteasomal system (Macario \& Conway de Macario 2007), but the situation with Hsp60 seems to be less clear, particularly in what pertains to the immunoproteasome.

Quintana: Yes, there are indications that cytokines can change the composition of some of the members of the proteasome. This is linked to the presentation of different self peptides from Hsp60.

Coates: I'd like to return to the blood. You are measuring antibodies in blood, and other people have been measuring heat shock proteins in blood, but what do we know about the effects of injection of high levels of HSPs into the blood, with measurable amounts of HSPs and antibodies? You'd have to inject a lot of HSP to get high levels.

Quintana: I don't recall any reports of this in the literature. We tried to generate a TLR4 knockout on the NOD background. HSPs are very important for diabetes, and one of the easiest ways to screen for the knockouts was to give them lipopolysaccharide (LPS) and get the survivors. Initially, we wanted to see whether injection of high levels of HSP would lead to some kind of endotoxin shock. We didn't get to high levels. We didn't really see anything, but we were looking for gross effects.

Miller-Graziano: The presentation highlights the classical way of getting anergic $T$ cells. This alteration in humans induces adaptive Treg. These adaptive Treg are a little bit different from the $\mathrm{CD} 4^{+} \mathrm{CD} 25^{+}$'natural' 'Treg seen in a mouse or rat system. The classical way to block these T cells' suppressive activity is to block their co-inhibitory molecules. This is what makes the TT antigen presentation possible: they up-regulate CD86, which binds preferentially to CTLA4 on the secondary T cells. I am interested in the idea that HSPs can up-regulate and down-regulate receptors. Did you see any up-regulation of CD86 or CTLA4 as a result of your HSP system? If you did assess receptor expression, did you assess blocking it? 
Quintana: Simplistically speaking, it is possible to take this anti-idiotypic antiHsp60 T cell and activate it either with a T cell or an APC. We did this. When we activate with DCs it leads to an expansion of the regulatory population, but if we activate it with a regulatory cell, on the one hand it will shut off the cell that is to be regulated but on the other hand it becomes anergic. In effect, it is regulating the regulators. It is shutting off what it has to shut off, then it is shutting itself off. Regarding the CD80/CD86, when $\mathrm{T}$ cells are activated they up-regulate their surface levels of co-stimulatory molecules. We blocked with these antibodies and then the whole system doesn't work. Just to complicate things a bit more, human Tregs $\left(\mathrm{CD} 4^{+} \mathrm{CD} 25^{+}\right)$are characterized by high expression of MHC class II. At a certain point the two systems are interconnected and cross-regulate each other.

Asea: In your system the anti-Hsp60 Treg express TLR2. Did you try to generate any anti-Hsp70 Treg? If so, would you predict that they would express TLR4 on their surface?

Quintana: This is an extension of some work we did with DNA vaccination. We got nice responses in terms of regulation of the disease by vaccination with Hsp70. We have some data showing that we also induced some anti-idiotypic regulators. I never got a good anti-Hsp70 cell line. Theoretically I would expect it to work.

Pockley: A lot of the early work relating to the measurement of circulating antibodies derived from their relationship to both autoimmune disease and particularly cardiovascular disease/atherosclerosis. Georg Wick's group in Innsbruck drove these studies. Qingbo Xu, who is now in London showed in a mouse model that if anti-HSP antibodies are administered to an ApoE knockout mouse (an animal model of cardiovascular disease) this markedly accelerates the development of disease (Foteinos et al 2005). This adds to some of the previous data which suggest in vitro at least that if these antibodies are added to cultured endothelial cells they induce cytotoxicity of these endothelial cells. The inference from this is that while it has been known for some time that stress protein expression within vascular bifurcations is up-regulated, the fact that antibodies can induce cytotoxicity suggests that there is some membrane or surface expression of these proteins to allow the antibodies to elicit their effect. It is also worth trying to differentiate between the baseline antibodies and their affinity levels, and then elevated levels of antibodies, to see whether the latter have different affinities to the naturally occurring ones. It is also interesting to look at the isotype profile of the antibodies: are they $\operatorname{IgG1}$ ? This would provide insight into the nature of the immune response that is driving the generation of these antibodies.

Quintana: Obviously, the antibodies we are measuring are low affinity. They are not diluted, so even if they are of low affinity they might be relevant. The NOD mice are rich in natural antibodies to Hsp60. I did a fusion of spleens from naïve NOD mice to generate monoclonals. We raised many HSP-specific monoclonals 
which are IgMs. One of the controls we use, to show that we can inhibit the activation of HSPs with TLR2, is one of those monoclonals. We don't know how many of those antibodies in this Hsp60-specific repertoire are inhibitory, but we know that at least one of them is. In diabetes there is some good literature showing that antibodies of Th1-associated isotypes are linked with the progression of diabetes.

Pockley: I think it is important to differentiate between types of antibodies, which is what you are doing. There is some work from Zoltan Prohászka which has demonstrated that antibodies against human HSP60 and mycobacterial Hsp65 differ in their complement-activating ability (Prohászka et al 1999).

Quintana: There was some work by him on HSP-specific antibodies (Veres et al 2002). They have shown that there are complement-fixing isotypes associated with disease expression.

Pockley: We did some work in some subjects with established hypertension. We found much higher levels of anti-HSP antibody in those individuals. When we refer these back and look at the immunoglobulin levels in individuals with established hypertension, these are elevated as well. If we correct everything for the non-specific effect of the disease process on immunoglobulin levels, then the levels of the anti-stress protein antibodies were no different to the controls. We also need a baseline against which we can compare antibody levels.

Quintana: In the case of the NOD work we've done, it is interesting that we had the whole library of peptides for Hsp70, and none of these were picked up.

\section{References}

Foteinos G, Afzal AR, Mandal K, Jahangiri M, Xu Q 2005 Anti-heat shock protein 60 autoantibodies induce atherosclerosis in apolipoprotein E-deficient mice via endothelial damage. Circulation 112:1206-1213

Macario AJL, Conway de Macario E 2007 Molecular chaperones: multiple functions, pathologies, and potential applications. Front Biosci 12:2588-2600

Prohászka Z, Duba J, Lakos G et al 1999 Antibodies against human heat-shock protein (hsp) 60 and mycobacterial hsp65 differ in their antigen specificity and complement-activating ability. Int Immunol 11:1363-1370

Veres A, Szamosi T, Ablonczy M et al 2002 Complement activating antibodies against the human $60 \mathrm{kDa}$ heat shock protein as a new independent family risk factor of coronary heart disease. Eur J Clin Invest 32:405-410 